\title{
Descemet's Membrane
}

National Cancer Institute

\section{Source}

National Cancer Institute. Descemet's Membrane. NCI Thesaurus. Code C32454.

A thin hyaline membrane between the chief part of the sclera and the endothelial layer of the cornea. 